\title{
The Dynamic Knowledge Loop: Inter- and Transdisciplinary Cooperation and Adaptation of Climate Change Knowledge
}

\author{
Maria Hagemeier-Klose $\cdot$ Simone Annerose Beichler • \\ Bart Jan Davidse $\cdot$ Sonja Deppisch
}

Published online: 29 March 2014

(c) The Author(s) 2014. This article is published with open access at Springerlink.com

\begin{abstract}
The "dynamic knowledge loop" explores processes of knowledge generation, knowledge exchange, and social learning in inter- and transdisciplinary cooperation and relates them to adaptive capacity. Adaptive capacity building can reduce vulnerabilities and enhance the resilience of urban regions towards the impacts of climate change. We use a mix of empirical methods and apply the dynamic knowledge loop as an innovative analytical tool. The added value of inter- and transdisciplinary cooperation concerning knowledge generation and facilitation of social learning is discussed by applying the dynamic knowledge loop to research about a scenario-planning process and a participatory mapping exercise in the urban region of Rostock, Germany. The results demonstrate that the scenario planning process allowed for a consideration of complex interrelations that have the potential for an integration of different influences, perspectives, and knowledge forms. Scenario planning facilitated social learning by creating a platform for integration and exchange of different epistemologies and for considering alternative futures. The participatory mapping exercise demonstrated the scientific value of the integration of local knowledge as well. Building upon these results, we stress the importance of knowledge generation, knowledge exchange, and social
\end{abstract}

M. Hagemeier-Klose $(\bowtie) \cdot$ S. A. Beichler $(\bowtie)$.

B. J. Davidse · S. Deppisch

Research Group "plan B:altic - Climate Change and Spatial Development," Department of Urban Planning and Regional Development, HafenCity University Hamburg, 20457 Hamburg, Germany

e-mail: mariahagemeier@web.de

S. A. Beichler

e-mail: simone.beichler@gmx.de learning to build up adaptive capacity through different forms of cooperation between science and practice.

Keywords Adaptive capacity · Climate change $\cdot$ Interdisciplinary cooperation $\cdot$ Knowledge exchange $\cdot$ Social learning $\cdot$ Transdisciplinary cooperation

\section{Introduction}

Climate change is often referred to as one of the most threatening future challenges. As such, increasing adaptive capacity is important to increase the capability of actors to deal with the effects of climate change (Walker et al. 2002). Climate change poses new challenges for civil protection, such as dealing with high uncertainty regarding the risks related to climate change. Much is written about environmental knowledge, different forms of knowledge, and social learning, all expressing the advantages of participation and the need for combining knowledge (Häberli et al. 2001; Schreyögg 2002; Folke et al. 2003; Roux et al. 2006; Fry et al. 2008; Berkes 2009; Reed et al. 2010). Adaptation to the impacts of climate change demands interand transdisciplinary research including participatory processes that allow for the combination and integration of different forms of knowledge (Pohl and Hirsch Hadorn 2007; Fry et al. 2008; Reed 2008; Sanchez-Rodriguez 2009). However, a structured analysis of such participatory approaches that incorporates the dynamics of knowledge in adaptation to climate change is still missing. This article fills this gap by proposing the dynamic knowledge loop as an approach to analyze inter- and transdisciplinary cooperation in climate change research. The dynamic knowledge loop contributes to adaptive capacity building, giving 
a comprehensive overview of the different aspects of knowledge.

The article uses the dynamic knowledge loop to analyze processes of inter- and transdisciplinary cooperation within a research project on climate change adaptation in urban regions at the Baltic Sea coast. Interdisciplinary research bridges different scientific disciplines, for example, by using joint research concepts; transdisciplinary research crosses the borders of science and actively involves practitioners into the research process and the generation of knowledge (Mobjörk 2010). Moreover, climate change knowledge exists in different forms and actors; institutions or scientific disciplines hold various stocks of knowledge. Yet science and practice express a growing demand for adequate knowledge of adaptation and argue for an adaptation of knowledge as part of adaptive capacity and as a basis for adaptation measures or policies, which are both currently judged as insufficient (Smit et al. 2001).

Adaptation demands interdisciplinary cooperation, practice-science cooperation, science-practice exchange of results, and practice-practice cooperation across sectors. The objective of this study is to understand and analyze these processes in different contexts. Our project works on an interdisciplinary basis (natural sciences, social sciences, planning science, and geography) and engages in transdisciplinary research, intensively involving stakeholders from the urban region of Rostock, Germany. Through such new research, experiences, and learning processes, knowledge is generated, changed, exchanged, and embedded into new contexts. In this article, we use the dynamic knowledge loop to reflect upon these dynamic processes. The dynamic knowledge loop enables us to untangle the different steps of inter- and transdisciplinary cooperation, leading to a successive adaptation of knowledge.

In the first part, theoretical considerations about processes of knowledge exchange, knowledge generation, adaptive capacity, and social learning are presented. This is followed by reflection on such processes in the Rostock case study region by applying the dynamic knowledge loop model. We provide insights into how inter- and transdisciplinary cooperation can initiate positive influences on adaptive capacity.

\section{Theoretical Framework}

This section provides an overview of the theoretical background and considerations embedding the developed framework into the wider research context. The first part describes the basic understanding of knowledge in the context of climate change. The second part deals with the concept of adaptive capacity in social-ecological systems with special emphasis on the combination of different kinds of knowledge and processes of social learning in adaptation to climate change.

\subsection{Climate Change Knowledge}

Knowledge about climate adaptation is crucial in the development of climate adaptation policies that incorporate deliberate consideration of how and when to act based on scientific evidence (Adger et al. 2009, p. 5). Following Ehrlich et al. (1999) and Endres (2003), we consider knowledge as objects (information) and models (theories) that are considered to be accurate and useful, because they have been organized and evaluated, explain the world around us, and shape the way we act and behave. Knowledge can take different forms; it is multifaceted and complex, implicit and explicit, static or continuously developing, and individual or distributed/shared (Bläckler 1995; Nonaka and Takeuchi 1995). Knowledge plays an important role in decision-making processes, often within an ideal idea about the role of rationality, for instance bounded rationality (Simon 1957, 1987) or communicative rationality (Habermas 1984, 1987). It is also acknowledged that in actual decision making knowledge is often ignored and used in a specific way or even manipulated, to legitimize certain viewpoints or decisions (Flyvbjerg 1998, 2001). There is a strong link between power relations in society and the way in which these power relations influence the use of knowledge. In the context of climate change, stakeholders use different forms of knowledge for decision making. Not only scientifically generated knowledge, but also, and perhaps more importantly, local knowledge, practical knowledge, and strategic knowledge play a role and are taken into account in this study. The generation of climate change knowledge for decision making builds upon individual experiences, epistemologies, and norms, and takes place via interaction and exchange; the actual use of knowledge is largely shaped by power relations.

Smit et al. (2001, p. 880) argue that "current knowledge of adaptation and adaptive capacity is insufficient for reliable prediction of adaptations; it is also insufficient for rigorous evaluation of planned adaptation options, measures and policies of governments." Both scientists and practitioners affirm such a deficit of knowledge (White et al. 2001; Weber 2006; Frommer 2011). Available knowledge can be used inappropriately (White et al. 2001) or denied, downplayed, or disbelieved, resulting in low awareness or false assessments of potential impacts or adaptation options (Grothmann and Patt 2005). Additionally, there is a mismatch between scientifically generated knowledge and knowledge requested by practitioners. Here knowledge integration is of great importance, because local stakeholders do not (only) rely on scientific results, but 
actively construct their own knowledge (Irwin et al. 1996). Moreover, scientific knowledge often lacks relevance and usability for practitioners as it often focuses heavily on theoretical issues, lacks local examples, and fails to address real world problems. Therefore, learning and knowledge production for practical problem solving needs exchange and cooperation among scientists and practitioners (Fry et al. 2008).

\subsection{Adaptive Capacity in Social-Ecological Systems}

An urban region, such as Rostock, can be regarded as a social-ecological system. Society depends on goods and services from nature and takes actions that influence ecosystems. Therefore, society cannot be considered without its environment (Reid et al. 2005). As presented by Adger et al. (2007), adaptation to climate change includes all initiatives and measures undertaken to reduce the vulnerability of ecological and social systems. Adaptation is a process, action, or outcome that enables a system to cope with changing conditions (Smit and Wandel 2006). Many observers argue that the adaptive capacity within naturesociety systems must increase (Lebel et al. 2006). In this article, we understand adaptive capacity as the capacity of actors in the social-ecological system to manage resilience (Walker et al. 2002). Other aspects of adaptive capacity in the context of the social-ecological system approach include the ability to learn from mistakes (Adger 2003), the generation of experiences of dealing with change and uncertainties (Berkes et al. 2003), and the cultivation of a capacity for innovation (Armitage 2005). Folke et al. (2003) have formulated several elements that can serve to increase the capacity to promote resilience: (1) learning to live with change and uncertainty; (2) combining different types of knowledge for learning; (3) creating opportunities for self-organization that enhances social-ecological resilience; and (4) nurturing sources of resilience for renewal and reorganization. In this article we particularly focus on the second element, which we separate into combining different kinds of knowledge on the one hand and (social) learning on the other.

\subsubsection{Combining Different Kinds of Knowledge}

Knowledge sharing, anticipating, and forecasting, as well as social learning, are gaining importance in climate change adaptation and are highlighted as key factors of building adaptive capacity. Thus they are all important prerequisites for managing resilience (Walker et al. 2002; Fabricius et al. 2007). Several authors emphasize the importance of synthesizing scientific knowledge with local and practical knowledge (Sanchez-Rodriguez 2009). Such combinations offer the potential to create joint results that are better in quality, transparency, and legitimacy than results obtained by science or practice separately (Klein et al. 2001; Mittelstraß 2004; Pohl and Hirsch Hadorn 2007; Reed 2008). This also holds true for specific assessments and indicator development. For example, the assessment of cultural ecosystem services needs to take the local cultural context into account. Participatory mapping is a method that brings local experiences of stakeholders into a spatial context (Fagerholm et al. 2012). Vulnerability assessments need to include stakeholders in order to identify case study-specific indicators and account for local vulnerability characteristics (Hutton et al. 2011). Through mutual learning, the knowledge and the capacities of all participants, scientists and practitioners, can be improved (Häberli et al. 2001; Burger and Kamber 2003; Zierhofer and Burger 2005). Arguing in this direction, Berkes (2009) stresses the importance of joint knowledge generation, joint problem solving, bridging organization, and continuous reflection on ongoing processes.

\subsubsection{Social Learning in Adaptation to Climate Change}

Social learning occurs when emergent, contextualized knowledge is coupled with social interactions. In these instances, individuals and the resources at stake are brought into new relationships with each other. This forms the basis for practice-driven policy processes that are informed by multistakeholder knowledge generation (Jiggings et al. 2007). Bridging different efforts to define social learning, Reed et al. (2010) have elaborated a definition of social learning that distinguishes between processes of individual learning, knowledge generation, knowledge exchange, and social learning. They maintain that a learning process can only be considered as social learning if it demonstrates that the individuals involved have undergone a change in their understanding. For example, leaning can occur via the recall of new information or a change in their attitudes or epistemological beliefs. A process that results in social learning must go beyond the individual level and can only occur through social interactions between actors (Reed et al. 2010). Social learning improves adaptive capacity with regard to unpredictable and uncertain social and environmental change (Folke 2006).

The literature on social learning distinguishes three learning loops, each with its own characteristics. Singleloop learning can adapt and optimize existing instruments or problem solving procedures while retaining current norms and values (Argyris and Schön 2002; Hargrove 2002; Schreyögg 2002). In the context of climate change adaptation, single loop learning can occur as a response to changing conditions. The height of dikes can be adapted to new climate change scenarios, for example, but the 
adequateness of dikes as an appropriate measure is not questioned.

Double loop learning is more oriented to change and therefore can alter adaptation capacities more fundamentally (Schreyögg 2002). When existing norms and values are questioned, the creation of new, innovative measures or strategies is supported. Double loop learning occurs when existing problem-solving procedures fail or when they are proved to be inadequate. This can happen as a result of a disaster or when individuals or groups are confronted with new challenging problems for which the existing procedures are considered inappropriate (Argyris and Schön 2002; Hargrove 2002; Schreyögg 2002).

Triple loop learning changes norms and values if they are perceived to be no longer appropriate, for instance when confronted with climate change. These learning processes also consider changes in governance structures (Hargrove 2002; Pahl-Wostl 2002, 2009; Pahl-Wostl et al. 2007; Armitage 2008). For example, paradigms for urban development or cooperation structures might be changed due to climate change.

Transdisciplinary knowledge exchange between science and practice can serve as initiating stimulus for such social learning processes. In the next section we present the methods we have used to develop such a transdisciplinary process. We introduce the dynamic knowledge loop as a method to analyze processes of knowledge generation, knowledge exchange, and social learning.

\section{Research Design}

Rostock was chosen as an example of a German urban region at the Baltic Sea as its exposure to climate change impacts is rather high, but no efforts of adaptation to climate change had taken place before our research process started. The urban region of Stockholm in contrast had already taken first steps to incorporate climate change considerations into planning. In the transdisciplinary process we have applied four types of qualitative empirical research methods: workshops, focus group discussions, participatory mapping, and semistructured interviews. The qualitative approach gives the opportunity to intensively integrate the interviewees and workshop- and focus group participants into the research and to get into an open transdisciplinary dialogue with them (Mayring 2002; Flick et al. 2009). The first three methods were applied in the case study of Rostock, serving as methods for data collection as well as an arena in which processes of knowledge exchange and social learning could be observed. The semistructured interviews were conducted in the case study of Stockholm, to integrate other perspectives and to reflect on the transferability of the results.

\subsection{Scenario Workshops and Focus Group Discussions}

During a period of 2.5 years, from 2010 to 2012, we conducted a series of three scenario workshops in Rostock (Hagemeier-Klose et al. 2012).The main objective of the workshops was to discuss the impacts of climate change in relation to other aspects of future development and to develop adaptation strategies and measures. During the first workshop, the focus was on the impacts of climate change, key factors for spatial development, and the interactions between those factors. Based on these discussions, four different future scenarios were developed and discussed during the second workshop. In the last workshop, four revised final scenarios and their specific future development served as a basis to discuss potential adaptation strategies and measures. The 30-40 participants of the single workshops came from very different backgrounds, ranging from administrators and politicians to nongovernmental organizations and businesses, thus a good mixture of relevant local and regional institutions was achieved.

Focus group discussions were conducted after each workshop with a core group, integrating scientists from our research group and representatives of (1) the Urban Planning Office, (2) the Environmental Agency of the City of Rostock, (3) the District Planning Office of the County of Rostock, (4) the Regional Planning Agency of the Rostock region, and (5) the State Agency for Agriculture and Environment of Mecklenburg-Vorpommern. This core group served as a knowledgeable reference group to reflect on workshop results. Knowledge exchange and learning processes within the workshops as well as recommendations for the scenario process and the facilitation of social learning were discussed.

\subsection{Focus Group Discussions and Participatory Mapping with Local Stakeholders}

In order to gain comparative results from local stakeholders outside the scenario process, an empirical survey consisting of six focus groups with a range of local stakeholders from different disciplines was conducted. The 36 participants represented local planning institutions, economic organizations, an environmental NGO, civil protection department, science department, and a social NGO.

The discussions followed a semistructured approach, characterized by a flexible use of guiding questions. These discussions were followed by a participatory mapping exercise aimed at integrating local knowledge into the spatial assessment of cultural ecosystem services and perceived vulnerability (Beichler 2013). As a first step, the participants mapped areas related to six different cultural ecosystem services on printed topographical maps of the urban region of Rostock. In the second step, bearing in 
mind the service areas allocated, participants were asked to map out areas they would avoid during an extreme event such as a heat wave, or flood. Only extreme events were considered because these can be most readily perceived by individuals, in contrast to events, such as drought, that develop gradually and have continuously changing parameters. The maps were digitized in ArcGIS 10 and analyzed using spatial statistics.

\subsection{Expert Interviews in Stockholm}

A series of 10 semistructured interviews (Meuser and Nagel 1991) was conducted in the urban region of Stockholm for different aims. Firstly, the interviews aimed at validating the transferability of results on knowledge generation, exchange, and learning from the Rostock case study in a different urban region at the Baltic Sea coast with similar potential climate change impact, but a broader regional context. Secondly, the stakeholders in the urban region of Stockholm already undertook first steps in dealing with the topic of climate change. Thus, they were able to complement and discuss the results of the scenario planning process in the urban region of Rostock from a different perspective. The interviewees included experts from the city planning authority, the city's environmental administration, regional planning, research institutions, civil protection authority, water administration, city association, and an environmental NGO. In this context, the term expert refers to an actor who provides direct access to and first-hand insight into the field of research (Bogner and Menz 2002). In order to gain comparable results, the guiding questions were similar to the ones used in the focus groups in Rostock. Moreover, results from the scenario planning process in Rostock (Hagemeier-Klose et al. 2012) were briefly presented and discussed. The transdisciplinary work presented was seen to be of great importance for knowledge exchange and social learning. The interviewees stated that not enough like this is being done in the Stockholm region and thus the situation should be improved.

The empirical results were analyzed with regard to processes of knowledge integration, knowledge generation, knowledge exchange, and social learning. Carrying out the empirical assessment, the dynamic knowledge loop was developed as a tool that allows for a structured presentation and analysis of the results.

\subsection{The Dynamic Knowledge Loop}

The dynamic knowledge loop (Fig. 1) explores the dynamic processes of "adaptation of knowledge" or social learning (light grey background in Fig. 1), which leads to changes in "knowledge of adaptation" or knowledge relevant for adaptation to climate change (dark grey circle

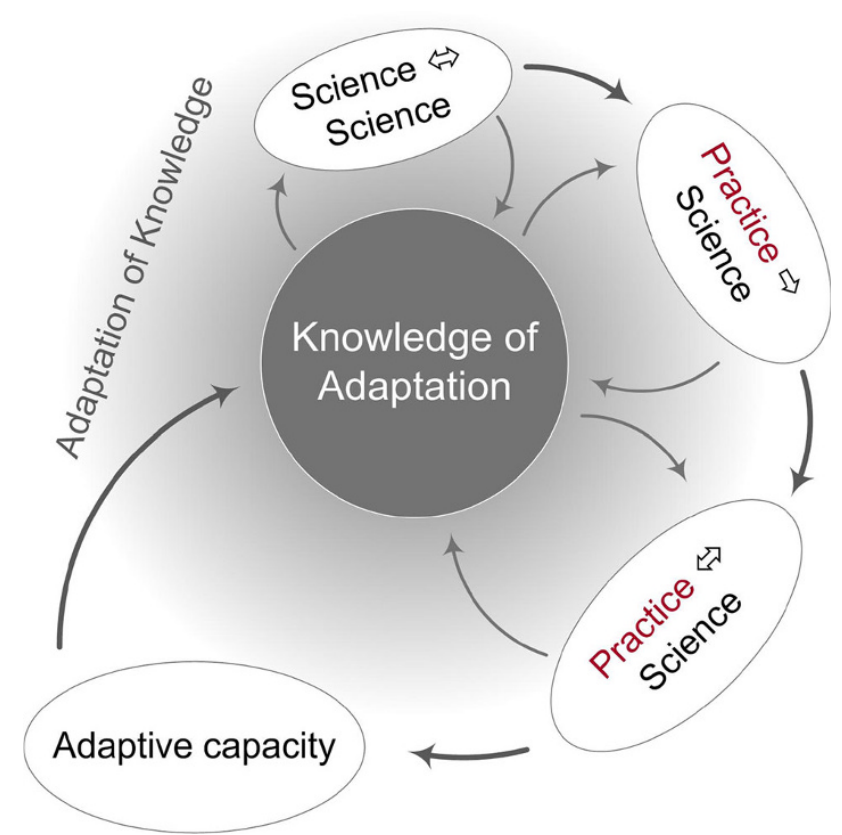

Fig. 1 The dynamic knowledge loop. Source concept and illustration by M. Hagemeier-Klose and S. A. Beichler

Fig. 1). Learning takes place in the different kinds of interand transdisciplinary cooperation between science and practice (white circles Fig. 1). As a result of the interactive cooperation in each of these circles, the knowledge of adaptation is altered in a reflection loop, which is indicated by the small arrows in Fig. 1. In the loop's outer ring, the big arrows represent the sequence of the overall process, resulting in an altered adaptive capacity, which can be seen as the goal of the adaptation of knowledge.

\section{Results}

In this section, we present the results of the transdisciplinary process in Rostock on combining knowledge for social learning by using the dynamic knowledge loop to structure the analysis. Furthermore, we explore how the different forms of social learning can contribute to adaptive capacity building. Creative ideas for constructing a platform for knowledge exchange and social learning to enhance adaptive capacity also are presented.

\subsection{First Loop: Science-Science}

The first loop describes the knowledge generation and exchange among the participating scientific disciplines, in our case planning sciences, social sciences, natural sciences, and geography. The intensive interdisciplinary work in preparing the scenario planning process supported single loop learning. An adaptation and enhancement of 
knowledge took place, as the preparation of the transdisciplinary process uncovered specific needs for interdisciplinary coordination in order to ensure the practical applicability of results. To exemplify, the term adaptive capacity has a different meaning applied in social or natural sciences, thus an integrated understanding needed to be found. Moreover, in order to find a shared definition of the urban region, demands of natural scientists in terms of geographical extent and spatial resolution to study vulnerability and climate change impacts had to be matched to the demands of social and planning sciences in terms of administrative boundaries. Throughout the interdisciplinary process, knowledge was combined and generated, leading to a more holistic view and enhancing individual approaches and group results.

\subsection{Second Loop: One-Way Practice-Science}

The second loop describes the integration of practical or local knowledge into scientific research by collecting empirical data. We integrated practical knowledge into the preparation of the scenario workshops by including information, evaluations, and perspectives of the core group. Data needs and assessments of key factors for the future development of the case study region (for example, population density and development) were shared and discussed with the scientists. Thus, single loop learning occurred by combining the practical/local perspectives with scientific knowledge, which led to an adaptation of knowledge about the social-ecological system of the urban region of Rostock. The core group discussed and selected the key factors to be considered in the scenario process. This allowed for a more holistic perspective on the socialecological system and for a practice oriented analysis.

During the participatory mapping sessions, local knowledge was brought into a spatial context. This approach revealed a considerable amount of valuable data for spatial analysis of the social-ecological system. In total 674 areas that covered $280 \mathrm{~km}^{2}$ of the study area were identified for the different cultural ecosystem services. The map in Fig. 2 illustrates that the different categories of cultural ecosystem services aesthetics/inspiration, spiritual/ religious, cultural heritage/identity, recreation, knowledge/ education, natural heritage/intrinsic value of biodiversity and the single entries of the participants significantly overlap. In several places the entries of the participants are so dense that the different categories and associated colors obscure each other. This illustration on the one hand highlights that participants' entries coincide and on the other hand points out the multifunctional character of specific areas. These results enabled us to identify and reflect upon unique characteristics of the case study area, for example, the multifunctional character and importance of the forest area of Rostocker Heide, the harbor areas, and the inner city area (Fig. 2). The results concerning vulnerability to climatic extreme events revealed insights into local conditions as perceived by local stakeholders. Between 40 and $70 \%$ of the service areas identified are areas avoided during/or after an extreme event. Altogether, the participatory mapping results have a high added value. They permit analysis of local conditions of the socialecological system in Rostock's urban region under climate change, which can be used for indicator development and validation. Single loop learning occurred by combining scientific knowledge and local perspectives. This new knowledge was scientifically generated through the spatial analysis of local knowledge.

\subsection{Third Loop: Two-Ways Practice-Science}

The third loop of the dynamic knowledge loop explores transdisciplinary cooperation and presents knowledge generation and exchange among science and practice. Hereby, an integration of scientific and practical/local perspectives and evaluations could be achieved.

From the scientific perspective, single loop learning could be observed, provoking a far-reaching adaptation of newly generated and combined knowledge about the social-ecological system of the urban region of Rostock. Better knowledge about feedbacks, interrelations, and interdependencies among the different key factors impacting future development, as well as in relation to climate change impacts, was generated in the scenario workshops. The practitioners identified multiple feedbacks, assessed key factors, and the presented possible development paths from their perspective. They identified extreme weather events as the most threatening consequence of climate change with strong negative influences on most key factors perceived to be of great importance for future spatial development. The key factors, viewed to be most affected by climate change, were environmental conditions and tourism. The practitioners perceived huge negative influences on water resources, the development and quality of openspace areas, agriculture, and forestry caused by all climate change factors. Tourism was perceived to be strongly affected by extreme weather events and sea level rise, but also potentially positively influenced by increasing temperature. New topics were integrated into the discussions that were previously not considered by the scientists, such as health issues or the problem of drinking water supply, which was perceived to be of high relevance for the city of Rostock. Consequently, the two-ways practice-science cooperation induced single loop learning, enhanced the preparation of the scenarios as well as other scientific work, and fostered a more holistic perspective, all viewed as crucial to integrating knowledge and dealing with 


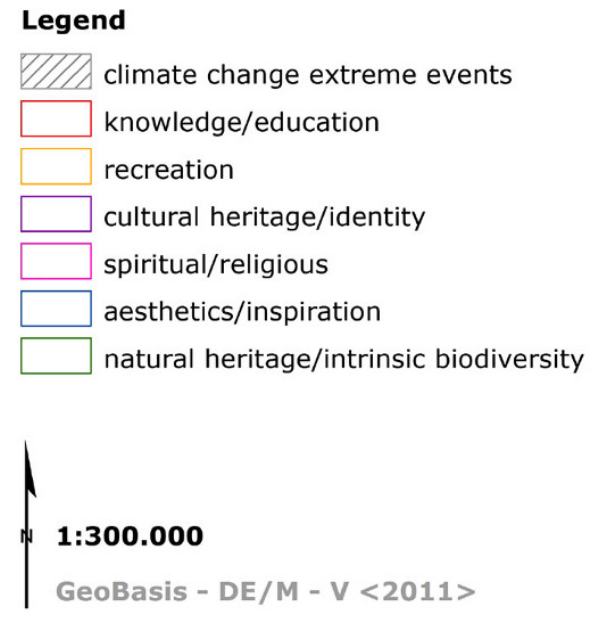

Fig. 2 Results of the participatory mapping exercise of cultural ecosystem services in the urban region of Rostock, Germany. The colored lines represent the individual entries of the participants, the different classes of cultural ecosystem services are color coded (see legend). Multifunctional areas are indicated where colors obscure each other-for example, in the middle part of the map (city center) and northeast (Rostocker Heide). Grey striped patterns illustrate areas

complexity preparatory to generating a locally specific and practically relevant analysis.

From the practitioners' point of view, single loop learning could be observed, which also enhanced the knowledge of the practitioners about the urban region of Rostock. This was confirmed by focus group results. Discussants stated that their knowledge was enhanced about climate change, adaptation options, complex interrelations, and the various factors that play a role in future development was enhanced. This learning process was initiated through scientific input and the different perspectives of other participating stakeholders. The topic of drinking water, for example, revealed various significant feedbacks and interdependencies including climate change and close connections between the city and its hinterland that demanded close cooperation.

Moreover, starting points for future adaptation processes were discovered. The participants argued that they learned more about current priorities, responsibilities, and potential contacts to engage with in adaptation in the urban region of avoided during extreme events. Source map prepared by S. A. Beichler combines results of the participatory mapping exercise in Rostock. Background topographical map (DTK25) (CGeoBasis$\mathrm{DE} / \mathrm{M}-\mathrm{V}<2011>$ was provided by "Landesamt für innere Verwaltung Mecklenburg-Vorpommern Amt für Geoinformation, Vermessungs und Katasterwesen". (Color figure online)

Rostock. Significant single loop learning was observed during the participatory mapping exercises. Many participants stated that they have never consciously thought about the spatial distribution of many regional characteristics, for example, aesthetic areas in the Rostock region. Although the participants mapped areas individually, a dynamic exchange of knowledge about the urban region took place within the group during the whole process. Participants exchanged, for example, experiences with the accessibility of high value nature areas close to the city, like the Rostocker Heide. Group dynamics had a positive impact on the motivation of participants as well, since most of the participants had initial problems allocating spiritual/religious values to particular places in the city and region. But talking about the first entries by single participants of spiritual values on the map motivated the whole group to consider equivalent areas on their own. A similar dynamic could be observed during the mapping of areas they would avoid in case of extreme events. Initially most of the participants found it difficult to imagine that extreme heat or 
drought could affect them significantly. They never consciously thought about it. After an exchange of experiences during past events, they were able to reflect upon their own sensitivity to these extreme events, and then moved on to consider the impacts of other potential hazards. Many participants stated that they learned a great deal of new information about the urban region of Rostock, and they showed a high level of interest in information on local climate change impacts.

During the scenario workshops, double loop learning could also be observed, such as the reassessment of existing planning strategies that were judged to be inappropriate. Workshop participants questioned current land use management practices and current approaches to flood mitigation. When dealing with management strategies and concrete preventive measures, they highlighted the need for an integrated flood risk management, covering river and coastal flooding. Participants advocated closer regional cooperation in the execution of long-term measures like land use change and the creation of floodwater retention areas. This was seen to be of importance, as the urban region of Rostock might face remarkable storm flood risks in future due to sea level rise and growing river flood risks due to changes in precipitation regime. From their perspective, such measures could become more problematic due to a perceived increase of conflicting land use claims in the urban region. By discussing the topics with a systems approach and thinking in terms of alternatives, the participants moved away from routine problem-solving procedures, which can be interpreted as double loop learning. The focus group discussants expressed an increased awareness about the possibilities of very different potential future developments and associated uncertainties. In addition, they highlighted the value of scenarios to develop and evaluate robust adaptation strategies and measures. Despite this positive assessment of the scenario approach, the discussants criticized the high level of resources needed to apply the method. The practitioners from the core group, which were engaged in the methodology of creating the scenarios, mentioned as well difficulties experienced in communication and comprehension. They described it as an innovative method, which provokes participants to change their views about the future and which questions working routines, but one that is difficult for practitioners to execute without external assistance.

From the practitioner's point of view, double learning also occurred through improvement in their ability to deal with complexity and uncertainty. During the workshops potential measures when facing different climate change scenarios were discussed. Some of them such as enhancing biotope networks, devising special building forms, or developing other strategies were identified and highlighted to be suitable adaptation measures for different alternative futures. These so-called "no-regret" measures can be implemented when facing an uncertain future, without the risk of maladaptation.

\subsection{Adaptive Capacity Building}

Adaptive capacity among stakeholders can be increased by combining different kinds of knowledge for learning (Folke et al. 2003). On the one hand, the workshops highlighted the dynamic nature of knowledge. On the other hand, they emphasized the need to actively combine different knowledge sets in order to achieve learning. The social learning process in the workshops enhanced the adaptive capacity of participants, because internalization of information about climate change and its relation to other urban development factors occurred. This learning process turned theoretical knowledge into practical, usable knowledge. Participants stated that they had not seen the connection between their own working field and climate change, but that their awareness of the importance of incorporating adaptation into their work had increased. Newly generated knowledge and the increased awareness are important to supply the motivation for and the actual development of climate change adaptation strategies.

Besides the adaptation of knowledge, we were able to observe some processes of network building, which can lead to better opportunities for self-organization and an increased adaptive capacity. One focus group discussant called it a "climate change in cooperation" between the city of Rostock and its hinterland. Moreover, the scenario planning process and its results directly contributed to the decision to elaborate a framework concept on adaptation to climate change in the city of Rostock. General agreement on the contents of this concept was achieved, which can be interpreted as a first sign of institutionalization. This development shows a first step towards practice-practice cooperation, which is outside the scope of the research process of the current study.

The knowledge loop has demonstrated the added value of inter- and transdisciplinary cooperation. It shows how knowledge generation and social learning can function together and how they contribute to an increased adaptive capacity. In the following section, we take this process a step further by presenting creative ideas and reflections from the point of view of the practitioners from the case study regions Rostock and Stockholm to improve the conditions for adaptive capacity building.

\subsection{Enhancing Adaptive Capacity Building}

Discussants in the urban region of Rostock stated that it is important to have a local perspective. They saw a large difference between the "virtual or global knowledge, which 
cannot directly be experienced" and local knowledge, which can directly be experienced or linked to own experiences and knowledge. A discussant, who was not participating in the scenario planning process, stated that it would be important to focus not only on climate change topics, but also to embed discussion into "the bigger frame" of society and to focus on nature-society interrelations. According to practitioners, informal processes, such as the scenario planning process, were considered to be more important than formal committees or councils. Personal contacts, voluntary regional cooperation, or informal meetings (for example, with colleagues of different areas of responsibility) were described as fruitful and successful occasions for knowledge exchange on climate change or adaptation possibilities. Remarks suggesting such practice-practice cooperation were made by most of the discussants or interviewees. These comments supported the facilitation of exchange between cities from different regions or countries that share similar characteristics or face comparable climate change impacts. Regional cooperation efforts on topics important for the whole region, which cannot be handled by the municipalities alone or that need consideration at the regional scale, were proposed quite often. In one focus group, the idea of a "climate adaptation meeting" with an informal character emerged. By bringing together relevant stakeholders to discuss common problems and possible adaptation strategies, measures appropriate to many places in the Baltic could emerge. In combination with a regional discussion forum, regular public events for the exchange and presentation of climate change and adaptation knowledge were suggested in order to reach more relevant actors. Bringing stakeholders from very different areas of responsibility together to discuss topics, meet regularly, and to find common strategies was regarded as vital for knowledge exchange and social learning in adaptation to climate change. The management of existing knowledge was perceived as a key element that can form a basis for exchange and learning. One interviewee suggested a permanent facility for exchange within the Baltic Sea region: a conference boat that could serve as neutral meeting point for diverse discussions and seminars. Visits to the harbors of the different countries could promote knowledge exchange among stakeholders from different countries and could serve as an exhibition venue to attract media attention and expand public awareness.

\section{Discussion: Enhancing Resilience by Adaptive Capacity Building-A Challenge for Civil Protection in the Face of Climate Change}

Social learning improves adaptive capacity (Folke 2006) and adaptive capacity is important to increase the capabilities of actors to deal with the effects of climate change (Walker et al. 2002). These effects can have major implications in the context of civil protection, for instance the uncertain effects of floods, droughts, heat waves, and other risks related to climate change. Within the scenario planning process and the focus groups, adapting civil protection was viewed as a major future challenge of climate change. Not only coping with extreme events was argued to be of importance. The workshop participants expressed a need to change the structures of current civil protection and risk management. Regional cooperation and knowledge generation was regarded as especially important due to uncertain impacts and multitude of climate change related risks.

A common claim in the literature is that there is a lack of knowledge on adaptation, which is a constraining element in the implementation of adaptation efforts (Smit et al. 2001; White et al. 2001; Weber 2006; Frommer 2011). The case of Rostock and the expert interviews in Stockholm stress the importance of knowledge in decisionmaking about adaptation. The workshops in Rostock indicate that the supposed deficit in knowledge on climate adaptation is not necessarily a constraining element. Instead constraints are related to deficits in knowledge exchange, which creates a strong argument for transdisciplinary knowledge integration rather than the production of new knowledge. This is similar to what McCrum et al. (2009) describe as bringing together the knowledge that was previously circulating within two different knowledge networks. In line with the findings of Hanger et al. (2012) and Roux et al. (2006), the Rostock workshops revealed that current practices of knowledge exchange are problematic, an oversupply of knowledge and the scientific terminology often hampers communication, and participants' understanding and extraction of relevant knowledge for a specific decision or planning process is compromised. Participants formulated requests for local information and local feedbacks to support their decisions and opinions, a process of transdisciplinary exchange that contributes to the development of practical knowledge that can be transferred into action. Pahl-Wostl (2006) demonstrates that transdisciplinary cooperation promotes the development of context-dependent knowledge as an emergent phenomenon, which is a prerequisite to deal with the complexity of real-world problems. This approach should go beyond a mere transfer of knowledge and initiate a coproduction of knowledge through collaborative learning (Roux et al. 2006). By utilizing the dynamic knowledge loop, we were able to unravel the dynamics in knowledge of adaptation and the adaptation of knowledge. In planning literature such empirically based investigations of social learning are rare (Albert et al. 2012). This conceptual framework is needed to reflect and analyze different approaches to transdisciplinarity and associated learning processes needed (Mobjörk 2010). Our results demonstrate 
that the scenario planning process has led to single loop and double loop learning among the participants. Positive contributions of scenario planning to processes of social learning, the recognition of complexity, and the integration of different perspectives were also found by Albert et al. (2012).

Translating our findings into improved adaptive capacity underlines the importance of combining different kinds of knowledge to promote learning (Folke et al. 2003). This transdisciplinary knowledge exchange has positively contributed to the adaptive capacity among the participants. But this increased adaptive capacity does not necessarily lead to the implementation of adaptation policies and measures. O'Brien et al. (2006, p. 55), for instance, uses the example of Norway to stress that despite an assumed high adaptive capacity, adaptation is still unlikely to occur without institutional and financial support. The knowledge of adaptation, as captured in the dynamic knowledge loop, still has to be embedded in a broader social, economical, political, and institutional setting, which implies an additional practice-practice loop. In such a practice-practice loop, learning can possibly take place via knowledge exchange between different practical disciplines, perspectives, and so on or via joint knowledge generation among the practitioners, both during discussion of possible adaptation strategies and beyond.

The elaboration of the framework concept for adaptation to climate change in the city of Rostock is an interesting example. The different administrative bodies representing environmental affairs, construction and planning, social and health affairs, landscape and green areas, as well as civil protection, worked well together. They met to discuss the most important fields of action, to reflect upon coping in past extreme events and preparedness to potential future extreme events, as well as to make proposals for concrete adaptation measures. The researchers of plan Baltic were asked to actively take part in the discussion. The participants valued the knowledge exchange that occurred during that meeting and highlighted the need for cooperation for successful adaptation. The results of the meeting were then integrated into the framework concept, which is now framing the ongoing practice-practice cooperation in the urban region.

In practice-practice cooperation, the knowledge of adaptation usually is integrated within a broad range of other knowledge fields, and (more importantly) into existing and emerging power relations within society. These power relations strongly influence what knowledge is used in the decision-making processes or employed to legitimize or rationalize decisions. In the discussions, some of the practitioners stressed the fact that knowledge is power; simultaneously that power can define if this knowledge counts as relevant (Flyvbjerg 1998, 2001). The observed processes of social learning can contribute to an internalization of the knowledge of adaptation among decision makers and create a stronger position for the knowledge of adaptation.

\section{Conclusions}

The scenario planning process allowed for the integration of complex interrelations and the inclusion of very different influences, perspectives, and knowledge forms. The process facilitated social learning by creating space for the consideration of alternative future developments and by creating a platform for the integration and exchange of different epistemologies. The participatory mapping exercise showed the scientific value of the integration of local knowledge. But the empirical evidence for far-reaching influence on adaptive capacity building is limited, as mostly only single loop learning processes could be observed. As explored in the dynamic knowledge loop, intensive two-ways practice-science cooperation can provoke double loop learning processes that could unfold larger changes in adaptive capacity. Triple or multiple loop learning did not occur in our scenario planning process. A new, loose participant network was formed that can serve as a starting point for improved capacities for self-organization, but its persistence is unclear as long-term effects could not be studied during our research. Nevertheless, other authors and the empirical results above show that such informal networks and informal exchange and cooperation can act as incubators for new governance approaches and facilitators of adaptive capacity building (Gunderson 1999; Folke et al. 2005; van Herk et al. 2011).

Knowledge plays a crucial role in the context of adaptation to climate change. The development of inter- and transdisciplinary research methods is of special importance. These research styles integrate different kinds of knowledge and overcome constraints in the development of policies and strategies to adapt to the effects of climate change. To deal with this issue, we presented a novel way to analyze and understand the dynamic processes of transdisciplinary knowledge generation, knowledge exchange, and social learning. The proposed dynamic knowledge loop uncovers the characteristics of different kinds of cooperation and the effects they have on the knowledge of adaptation, as well as the adaptation of knowledge. We stress the importance of knowledge exchange, knowledge generation, and social learning to build up adaptive capacity through cooperation between science and practice.

Acknowledgments The authors would like to thank the research group plan B:altic for ongoing discussions. Special thanks go to Meike Othengrafen for the help in designing Figure 1. The research is funded by the HafenCity University and the German Federak Ministry of Research and Education through the Social-Ecological Research Programme (FKZ 01UU0909). 
Open Access This article is distributed under the terms of the Creative Commons Attribution License which permits any use, distribution, and reproduction in any medium, provided the original author(s) and the source are credited.

\section{References}

Adger, W.N. 2003. Social capital, collective action, and adaptation to climate change. Economic Geography 79 (4): 387-404.

Adger, W.N., S. Agrawala, M.M.Q. Mirza, C. Conde, K. O'Brien, J. Pulhin, R. Pulwarty, B. Smit, and K. Takahashi. 2007. Assessment of adaptation practices, options, constraints and capacity. In Climate Change 2007: Impacts, adaptation and vulnerability. Contribution of Working Group II to the fourth assessment report of the Intergovernmental Panel on Climate Change, ed. M.L. Parry, O.F. Canziani, J.P. Palutikof, P.J. van der Linden, and C.E. Hanson, 717-743. Cambridge, UK: Cambridge University Press.

Adger, W.N., I. Lorenzoni, and K. O'Brien (eds.). 2009. Adapting to climate change: Thresholds, values, governance. Cambridge: Cambridge University Press.

Albert, C., T. Zimmermann, J. Knieling, and C. von Haaren. 2012. Social learning can benefit decision-making in landscape planning: Gartow case study on climate change adaptation, Elbe valley biosphere reserve. Landscape and Urban Planning 105 (4): 347-360.

Argyris, C., and D. Schön. 2002. The learning organization (Die lernende Organisation), 2nd ed. Stuttgart: Klett-Cotta.

Armitage, D. 2005. Adaptive capacity and community-based natural resource management. Environmental Management 35 (6): 703-715.

Armitage, D. 2008. Governance and the Commons in a multi-level world. International Journal of the Commons 2 (1): 7-32.

Beichler, S.A. 2013. Exploring the use of participatory mapping in indicator development-The case of cultural ecosystem services in an urban region. In Proceedings of the joint workshop indication, integration and application of ecosystem services in decision making. Kiel, 6-8 May 2013.

Berkes, F. 2009. Evolution of co-management: Role of knowledge generation, bridging organizations and social learning. Journal of Environmental Management 90 (5): 1-11.

Berkes, F., J. Colding, and C. Folke (eds.). 2003. Navigating socialecological systems: Building resilience for complexity and change. Cambridge: Cambridge University Press.

Bläckler, F. 1995. Knowledge, knowledge work and organizations: An overview and interpretation. Organizational Studies 16 (6): $1021-1046$.

Bogner, A., and W. Menz. 2002. The theory-generating expert interview: Cognitive interest, knowledge forms, interaction (Das theoriegenerierende Experteninterview: Erkenntnissinteresse, Wissensformen, Interaktion). In Expert interviews: Theories, methods, application fields (Das Experteninterview: Theorien, Methoden, Anwendungsfelder), ed. A. Bogner, B. Littig, and W. Menz, 33-70. Wiesbaden: Springer Fachmedien.

Burger, P., and R. Kamber. 2003. Cognitive integration in transdisciplinary science: Knowledge as a key notion. Issues in Integrative Studies 21: 43-73.

Ehrlich, P.R., G. Wolff, G.C. Daily, J.B. Hughes, S. Daily, M. Daltona, and L. Goulder. 1999. Knowledge and the environment. Ecological Economics 20 (2): 267-284.

Endres, A. 2003. The knowledge society and its relation to informatics (Die Wissensgesellschaft und ihr Bezug zur Informatik). Informatik Spektrum 26 (3): 195-200.
Fabricius, C., C. Folke, G. Cundill, and L. Schultz. 2007. Powerless spectators, coping actors, and adaptive co-managers: A synthesis of the role of communities in ecosystem management. Ecology and Society 12 (1): 29.

Fagerholm, N., N. Käyhkö, F. Ndumbaro, and M. Khamis. 2012. Community stakeholders' knowledge in landscape assessments-Mapping indicators for landscape services. Ecological Indicators 18: 421-433.

Flick, U., E. von Kardorff, and I. Steinke. 2009. Qualitative research: A handbook (Qualitative Forschung: Ein Handbuch). Reinbek: Rowohlt.

Flyvbjerg, B. 1998. Rationality and power: Democracy in practice. London and Chicago: The University of Chicago Press.

Flyvbjerg, B. 2001. Making social science matter, why social inquiry fails and how it can succeed again. Cambridge: Cambridge University Press.

Folke, C. 2006. Resilience: The emergence of a perspective for social-ecological systems analyses. Global Environmental Change 16 (3): 253-267.

Folke, C., J. Colding, and F. Berkes. 2003. Synthesis: Building resilience and adaptive capacity in social-ecological systems. In Navigating social-ecological systems: Building resilience for complexity and change, ed. F. Berkes, J. Colding, and C. Folke, 352-387. Cambridge: Cambridge University Press.

Folke, C., T. Hahn, P. Olsson, and J. Norberg. 2005. Adaptive governance of social-ecological systems. Annual Review of Environment and Resources 30: 441-473.

Frommer, B. 2011. Climate change and resilient society: Utopia or realistic option for German regions. Natural Hazards 58 (1): 85-101.

Fry, P., F. Bachmann, L. Bose, M. Flury, R. Förster, A. Kläy, C. Küffer, and C. Zingerli. 2008. From implicit know-how to explicit theses: Inter- and transdisciplinary knowledge exchange (Vom impliziten Know-how zu expliziten Thesen: Inter- und transdisziplinärer Wissensaustausch). Gaia: Ökologische Perspektiven für Wissenschaft und Gesellschaft 17 (3): 318-320.

Grothmann, T., and A. Patt. 2005. Adaptive capacity and human cognition. Global Environmental Change 15 (3): 199-213.

Gunderson, L. 1999. Resilience, flexibility and adaptive management-Antidotes for spurious certitude? Conservation Ecology 3 (1): 7.

Habermas, J. 1984. The theory of communicative action: Reason and the rationalization of society, vol. 1. Boston: Beacon Press.

Habermas, J. 1987. The theory of communicative action: Lifeworld and system: A critique of functionalist reason, vol. 2. Boston: Beacon Press.

Hagemeier-Klose, M., M. Albers, S. Beichler, B.J. Davidse, S. Deppisch, S. Hasibovic, and M. Richter. 2012. Results of the 3rd scenario workshop (Ergebnisbericht des 3. Szenario-Workshops). https://www.hcu-hamburg.de/research/forschungspro jekte/planbaltic/informationsmaterial/. Accessed 4 March 2014.

Hanger, S., S. Pfenninger, M. Dreyfus, and A. Patt. 2012. Knowledge and information needs of adaptation policy-makers: A European study. Regional Environmental Change 13 (1): 91-101.

Hargrove, R. 2002. Masterful coaching, revised edition. San Francisco: Jossey-Bass/Pfeiffer, Wiley.

Hutton, C.W., S. Kienberger, F.A. Johnson, A. Allan, V. Giannini, and R. Allen. 2011. Vulnerability to climate change: People, places and exposure to hazard. Advances in Science and Research 7: 37-45.

Häberli, R., A. Bill, J.T. Klein, R. Scholz, and M. Welti. 2001. Synthesis. In Transdisciplinarity: Joint problem-solving among science, technology, and society-An effective way for managing complexity, ed. J.T. Klein, W. Grossenbacher-Mansuy, R. Häberli, A. Bill, R. Scholz, and M. Welti, 6-21. Basel: Birkhäuser. 
Irwin, A., A. Dale, and D. Smith. 1996. Science and hell's kitchen: The local understanding of hazard issues. In Misunderstanding science?, ed. A. Irwin and B. Wynne, 47-64. Cambridge: Cambridge University Press.

Jiggings, J., E. Van Slobbe, and N. Röling. 2007. The organisation of social learning in response to perceptions of crisis in the water sector of the Netherlands. Environmental Science \& Policy 10 (6): 526-536.

Klein, J.T., W. Grossenbacher-Mansuy, R. Häberli, A. Bill, R.W. Scholz, and M. Welti. 2001. Transdisciplinarity: Joint problem solving among science, technology, and society-An effective way for managing complexity. Basel: Birkhäuser.

Lebel, L., J.H. Anderies, B. Campbell, C. Folke, S. Hatfield-Dodds, T.P. Hughes, and J. Wilson. 2006. Governance and the capacity to manage resilience in regional social-ecological systems. Ecology and Society 11 (1): Article 19.

Mayring, P. 2002. Introduction to qualitative social research (Einführung in die qualitative Sozialforschung), 5th ed. Weinheim: Beltz Studium.

McCrum, G., K. Blackstock, K. Matthews, M. Rivington, D. Miller, and K. Buchan. 2009. Adapting to climate change in land management: The role of deliberative workshops in enhancing social learning. Environmental Policy and Governance 19 (6): 413-426.

Meuser, M., and U. Nagel. 1991. Expert interviews-Tried on numerous occasions, seldom heeded: An article on the qualitative method discussion (ExpertInneninterviews-vielfach erprobt, wenig bedacht: Ein Beitrag zur qualitativen Methodendiskussion). In Qualitative empirical social research: Concepts, methods, analyses (Qualitativ-empirische Sozialforschung: Konzepte, Methoden, Analysen), ed. D. Garz, and K. Kraimer, 441-471. Opladen: Westdeutscher Verlag.

Mittelstraß, J. 2004. Keyword transdisciplinarity (Stichwort Transdisziplinarität). In Encyclopedia philosophy and theory of science (Enzyklopädie Philosophie und Wissenschaftstheorie), vol. 4, ed. J. Mittelstraß. Stuttgart: Metzler.

Mobjörk, M. 2010. Consulting versus participators transdisciplinarity: A refined classification of transdisciplinary research. Futures 42 (8): 866-873.

Nonaka, I., and H. Takeuchi. 1995. The knowledge creating company: How Japanese companies create the dynamics of innovation. New York: Oxford University Press.

O’Brien, K., S. Eriksen, L. Sygna, and L.O. Naess. 2006. Questioning complacency: Climate change impacts, vulnerability, and adaptation in Norway. Ambio 35 (2): 50-56.

Pahl-Wostl, C. 2002. Towards sustainability in the water sector: The importance of human actors and processes of social learning. Aquatic Sciences 64 (4): 394-411.

Pahl-Wostl, C. 2006. The importance of social learning in restoring the multifunctionality of rivers and floodplains. Ecology and Society 11 (1): Article 10.

Pahl-Wostl, C. 2009. A conceptual framework for analyzing adaptive capacity and multi-level learning processes in resource governance regimes. Global Environmental Change 19 (3): 354-365.

Pahl-Wostl, C., M. Craps, A. Dewulf, E. Mostert, D. Tabara, and T. Taillieu. 2007. Social learning and water resources management. Ecology and Society 12 (2): Article 5.
Pohl, C., and G. Hirsch Hadorn. 2007. Principles for designing transdisciplinary research. Munich: Oekom Verlag.

Reed, M.S. 2008. Stakeholder participation for environmental management: A literature review. Biological Conservation 141 (10): 2417-2431.

Reed, M.S., A.C. Evely, G. Cundill, I. Fazey, J. Glass, A. Laing, J. Newig, B. Parrish, et al. 2010. What is social learning? Ecology and Society 15 (4): r1.

Reid, W.V., H.A. Mooney, and A. Cropper. 2005. Millennium ecosystem assessment: Ecosystems and human well-beingsynthesis report. Washington, DC: World Resources Institute.

Roux, D.J., K.H. Rogers, H.C. Biggs, P.J. Ahston, and A. Sergeant. 2006. Bridging the science-management divide: Moving from unidirectional knowledge transfer to knowledge interfacing and sharing. Ecology and Society 11 (1): Article 4.

Sanchez-Rodriguez, R. 2009. Learning to adapt to climate change in urban areas: A review of recent contributions. Current Opinion in Environmental Sustainability 1 (2): 201-206.

Schreyögg, G. 2002. Organizational change and organizational learning. Double course. Tutorial note for unit "Organization IV" (Organisationaler Wandel und organisationales Lernen. Doppelkurseinheit. Lehrbrief für Kurseinheit "Organisation $I V$ ”). Hagen: FernUniversität in Hagen.

Simon, H.A. 1957. Models of man: Social and rational; mathematical essays on rational human behavior in society setting. New York: Wiley.

Simon, H.A. 1987. Bounded rationality. In The New Palgrave: A dictionary of economics, 1st ed, ed. J. Eatwell, M. Milgate, and P. Newman, 266-268. London: Palgrave Macmillan.

Smit, B., and J. Wandel. 2006. Adaptation, adaptive capacity and vulnerability. Global Environmental Change 16 (3): 282-292.

Smit, B., O. Pilifosova, I. Burton, B. Challenger, S. Huq, R.J.T. Klein, and G. Yohe. 2001. Adaptation to climate change in the context of sustainable development and equity. In Climate Change 2001: Impacts, adaptation, and vulnerability. Contribution of Working Group II to the third assessment report of the Intergovernmental Panel on Climate Change, ed. J.J. McCarthy, O.F. Canziani, N.A. Leary, D.J. Dokken, and K.S. White, 877-912. Cambridge: Cambridge University Press.

van Herk, S., C. Zevenbergen, R. Ashley, and J. Rijke. 2011. Learning and action alliances for the integration of flood risk management into urban planning: A new framework from empirical evidence from The Netherlands. Environmental Science and Policy 14 (5): 543-554.

Walker, B., S. Carpenter, J. Anderies, N. Abel, G.S. Cumming, M. Janssen, L. Lebel, J. Norberg, et al. 2002. Resilience management in social-ecological systems: A working hypothesis for a participatory approach. Conservation Ecology 6 (1): Article 14.

Weber, E.U. 2006. Experience-based and description-based perceptions of long-term risk: Why global warming does not scare us (yet). Climatic Change 77 (1-2): 103-120.

White, G.F., R. Kates, and I. Burton. 2001. Knowing better and loosing even more: The use of knowledge in hazards management. Environmental Hazards 3 (3-4): 81-92.

Zierhofer, W., and P. Burger. 2005. Disentangling transdisciplinarity: An analysis of knowledge integration in problem-oriented research. Science Studies 20 (1): 51-74. 